\title{
Frequent paracetamol use and asthma in adults
}

\author{
Seif O Shaheen, Jonathan A C Sterne ${ }^{\star}$, Christina E Songhurst $†$, Peter G J Burney
}

\begin{abstract}
Background-The pulmonary antioxidant glutathione may limit airway inflammation in asthma. Since paracetamol (acetaminophen) depletes the lung of glutathione in animals, a study was undertaken to investigate whether frequent use in humans was associated with asthma.
\end{abstract}

Methods-Information was collected on the use of analgesics as part of a population based case-control study of dietary antioxidants and asthma in adults aged 16-49 years registered with 40 general practices in Greenwich, South London. The frequency of use of paracetamol and aspirin was compared in 664 individuals with asthma and in 910 without asthma. Asthma was defined by positive responses to questions about asthma attacks, asthma medication, or waking at night with shortness of breath. The association between analgesic use and severity of disease amongst asthma cases, as measured by a quality of life score, was also examined.

Results-Paracetamol use was positively associated with asthma. After controlling for potential confounding factors the odds ratio for asthma, compared with never users, was $1.06(95 \%$ CI 0.77 to 1.45$)$ in infrequent users (<monthly), 1.22 (0.87 to $1.72)$ in monthly users, 1.79 (1.21 to 2.65$)$ in weekly users, and 2.38 (1.22 to 4.64$)$ in daily users ( $p$ (trend) $=0.0002$ ). This association was present in users and nonusers of aspirin and was stronger when cases with more severe disease were compared with controls; amongst cases increasing paracetamol use was associated with more severe disease. Frequency of aspirin use was not associated with asthma when cases as a whole were compared with controls, nor with severity of asthma amongst cases. Frequent paracetamol use was positively associated with rhinitis, but aspirin use was not. Conclusions-Frequent use of paracetamol may contribute to asthma morbidity and rhinitis in adults.

(Thorax 2000;55:266-270)

Keywords: paracetamol (acetaminophen); asthma; adults

Production of reactive oxygen species and nitric oxide by inflammatory cells is increased in asthmatic individuals. ${ }^{1-3}$ This endogenous oxidant burden, and inhaled oxidants such as nitrogen dioxide, ozone and cigarette smoke, may contribute to the pathogenesis of asthma by causing epithelial damage and increasing bronchial responsiveness. ${ }^{1}$ The epithelial lining fluid of the airways contains antioxidants such as ascorbic acid and $\alpha$-tocopherol ${ }^{4}$ which may defend the lung against oxidative stress and thus limit the degree of airway inflammation in asthma. It has been proposed that a declining intake of dietary antioxidants has contributed to the rise in asthma in recent decades. ${ }^{5}$

Glutathione (GSH), an antioxidant in its reduced form, is present in very high concentrations in airway epithelial lining fluid. ${ }^{6}$ Animal studies indicate that GSH plays an important role in preventing oxidative damage to the lung, ${ }^{78}$ and levels of GSH in human airways are increased in individuals exposed to inhaled oxidants such as cigarette smoke ${ }^{6}$ and nitrogen dioxide, ${ }^{9}$ suggesting a similar protective response. GSH may also be involved in defence against the oxidative stress of asthma inflammation, as levels of total ${ }^{10}$ and oxidised ${ }^{11}$ GSH were higher in the airways of adults with mild asthma than in those of controls. Furthermore, the ability of GSH to downregulate the transcription factor $\mathrm{NF}-\kappa \mathrm{B},{ }^{12}$ and the negative association between alveolar GSH levels and bronchial responsiveness seen in asthmatic adults, ${ }^{10}$ suggest that higher levels of airway GSH may limit the severity of asthma.

Aside from its function as a pulmonary antioxidant, GSH plays a key role in the hepatic detoxification of drug metabolites ${ }^{13}$ and stores of GSH in the liver are depleted by the reactive metabolite of paracetamol (acetaminophen). ${ }^{14}$ In animals administration of paracetamol also depletes the lung of GSH in a dose dependent fashion. ${ }^{15} 16$ We hypothesised that, if frequent paracetamol ingestion has the same effect in humans, it could compromise pulmonary defences against oxidative stress and contribute to asthma morbidity.

\section{Methods}

As part of a population based case-control study of asthma in young adults in South London, primarily designed to investigate the role of dietary antioxidants in asthma, we asked participants to report how often they took paracetamol and aspirin. The study was based on 9709 individuals who responded to a survey of asthma morbidity, conducted during autumn 1996, in a random sample of adults aged 16-49 registered with 40 general practices in Greenwich, South London. ${ }^{17}$

Individuals were defined as "asthmatic" if they responded positively to any of the following three screening questions: Have you been woken by an attack of shortness of breath in the last 12 months? Have you had an attack of asthma in the last 12 months? Are you currently taking any medicine for asthma? These questions have been used previously to define asthma in adults of this age ${ }^{18}$ and have 
been shown to be predictive of bronchial hyperresponsiveness. ${ }^{19}$ Individuals who responded negatively to all three questions were defined as "non-asthmatic". The survey also asked whether participants had nasal allergies including hayfever. Those who responded positively to this question were designated as having "rhinitis".

Among asthmatic individuals, severity was measured in two ways: (1) by the frequency of waking at night with asthma symptoms in the previous month (mild (not woken at all); moderately severe (woken twice a week or less); very severe (woken three times a week or more)); (2) as a score, derived from Likert scale responses to 16 questions about the impact of asthma on activities and quality of life, which has been shown to be correlated with objective measures of asthma severity ${ }^{2021}$ and has been used previously in this population. ${ }^{17}{ }^{22} \mathrm{~A}$ higher score indicates a worse quality of life. Asthmatic individuals were also asked whether they had used a steroid inhaler on most days in the previous month.

Of the responders from the asthma survey we selected all 1438 (15\%) asthmatic individuals (cases) and a random sample of 2000 of the individuals without asthma (controls). These individuals were mailed a dietary and lifestyle questionnaire in September 1997. Nonresponders were sent the questionnaires again on two further occasions at 3-4 week intervals. Of those who were sent a questionnaire, 720 $(50.1 \%)$ cases and $980(49.0 \%)$ controls replied. We estimated from comparison of general practice lists in 1993 and 1996 that $10 \%$ of individuals moved per year; after allowing for this the overall response rate was $55 \%$. Based on information collected in the 1996 survey,

Table 1 Association between asthma and risk factors included in analyses

\begin{tabular}{|c|c|c|c|}
\hline Risk factor & $\begin{array}{l}\text { No. (\%) of cases } \\
\text { (total 664) }\end{array}$ & $\begin{array}{l}\text { No. (\%) of controls } \\
\text { (total } 910)\end{array}$ & Crude OR $(95 \%$ CI) \\
\hline \multicolumn{4}{|l|}{ Sex } \\
\hline Female & $412(62)$ & $538(59)$ & 1 \\
\hline Male & $252(38)$ & $372(41)$ & $0.88(0.72$ to 1.09$)$ \\
\hline \multicolumn{4}{|l|}{ Age group } \\
\hline $15-19$ & $65(10)$ & $55(6)$ & 1 \\
\hline $20-24$ & $86(13)$ & $72(8)$ & $1.01(0.63$ to 1.63$)$ \\
\hline $25-29$ & $88(13)$ & $104(11)$ & $0.72(0.45$ to 1.13$)$ \\
\hline $30-34$ & $98(15)$ & $153(17)$ & $0.54(0.35$ to 0.84$)$ \\
\hline $35-39$ & $107(16)$ & $181(20)$ & $0.50(0.32$ to 0.77$)$ \\
\hline $40-44$ & $100(15)$ & $143(16)$ & $0.59(0.38$ to 0.92$)$ \\
\hline $45-51$ & $120(18)$ & $202(22)$ & $0.50(0.33$ to 0.77$)$ \\
\hline \multicolumn{4}{|l|}{ Social class } \\
\hline I & $34(5)$ & $92(10)$ & $0.44(0.29$ to 0.69$)$ \\
\hline II & $202(30)$ & $327(36)$ & $0.74(0.57$ to 0.96$)$ \\
\hline IIINM & $201(30)$ & $241(27)$ & 1 \\
\hline IIIM & $117(18)$ & $146(16)$ & $0.96(0.71$ to 1.31$)$ \\
\hline IV/V & $110(17)$ & $104(11)$ & $1.27(0.91$ to 1.76$)$ \\
\hline \multicolumn{4}{|c|}{ Type of accommodation } \\
\hline Owned & $377(57)$ & $635(70)$ & 1 \\
\hline Rented & $287(43)$ & $275(30)$ & $1.76(1.43$ to 2.17$)$ \\
\hline \multicolumn{4}{|l|}{ Unemployed } \\
\hline No & $465(70)$ & $715(79)$ & 1 \\
\hline Yes & $179(27)$ & $174(19)$ & $1.58(1.25$ to 2.01$)$ \\
\hline Not stated & $20(3)$ & $21(2)$ & $1.46(0.79$ to 2.73$)$ \\
\hline \multicolumn{4}{|l|}{ Single parent } \\
\hline No & $567(85)$ & $831(91)$ & 1 \\
\hline Yes & $97(15)$ & $79(9)$ & $1.80(1.31$ to 2.47$)$ \\
\hline \multicolumn{4}{|l|}{ Smoking } \\
\hline Never & $306(46)$ & $445(49)$ & 1 \\
\hline $\mathrm{Ex}$ & $124(19)$ & $169(19)$ & $1.07(0.81$ to 1.40$)$ \\
\hline Current & $234(35)$ & $296(33)$ & $1.15(0.92$ to 1.44$)$ \\
\hline \multicolumn{4}{|c|}{ Passive smoking in household } \\
\hline No & $411(62)$ & $641(70)$ & 1 \\
\hline Yes & $253(38)$ & $269(30)$ & $1.47(1.19$ to 1.81$)$ \\
\hline
\end{tabular}

response rates were lower in men, in younger persons, and in current smokers.

The lifestyle questionnaire asked about potential risk factors for asthma, including smoking history (never/ex/current), exposure to passive smoke at home and at work, use of a gas cooker, ethnicity, total individuals living in the household, and family history of atopic disease (asthma, eczema or allergic rhinitis in parents or siblings). It also enquired about socioeconomic information including employment status (coded as "not known" if no information given), housing tenure (owned/ mortgaged or rented), use of a car, whether receiving benefits, whether a single parent, and current or last job. Current social class was classified in men and women according to the Registrar General's classification of occupations ${ }^{23}$ and was based on the subject's own occupation (or partner's occupation if the latter was classified higher); students were classified according to father's occupation; individuals with insufficient information on own occupation were assigned social class based on father's occupation at birth.

Participants were asked to specify how often they took aspirin and paracetamol (daily, weekly, monthly, <monthly, or never). If they reported taking one analgesic but did not provide information about the other, it was assumed that the latter was never taken. In January 1999 we mailed an additional questionnaire to individuals who, in the 1997 survey, had reported that they took either paracetamol or aspirin on a daily or weekly basis. This asked about indications for frequent analgesic use and about aspirin avoidance.

All analyses were done using the statistical package Stata. We used logistic regression to examine the association between analgesic use and asthma (all cases and cases of differing severity), after controlling for potential confounding factors. Amongst cases we also examined the association with the quality of life score (square root transformed) using linear regression. To examine the association between analgesic use and rhinitis we used logistic regression with inverse probability weighting and robust standard errors. This allows for the fact that asthmatic individuals had a higher probability of inclusion in the study than nonasthmatic individuals, and is necessary because of the strong association between asthma and rhinitis.

\section{Results}

Of the 1700 responders in 1997, 1574 (664 cases and 910 controls) had complete information on analgesic use and potential confounding factors and were included in analyses. Table 1 shows the distribution of cases and controls according to risk factors for asthma. Compared with controls, cases were younger, of lower social class, and were more likely to be living in rented accommodation, unemployed, a single parent, and exposed to passive smoking at home. Participants' smoking habits were not related to asthma. 
Table 2 Association between asthma and frequency of analgesic use

\begin{tabular}{|c|c|c|c|c|}
\hline & Cases N (\%) & Controls N (\%) & Crude OR $(95 \%$ CI) & OR $(95 \% C I)^{*}$ \\
\hline \multicolumn{5}{|l|}{ Aspirin } \\
\hline Never & $403(61)$ & $537(59)$ & 1 & 1 \\
\hline$<$ Monthly & $166(25)$ & $254(28)$ & 0.87 (0.69 to 1.10$)$ & $1.04(0.81$ to 1.35$)$ \\
\hline Monthly & $49(7)$ & $66(7)$ & $0.99(0.67$ to 1.46$)$ & $0.97(0.64$ to 1.48$)$ \\
\hline Weekly & $33(5)$ & $39(4)$ & $1.13(0.70$ to 1.82$)$ & $1.01(0.60$ to 1.70$)$ \\
\hline Daily & $13(2)$ & $14(2)$ & $1.24(0.58$ to 2.66$)$ & $\begin{array}{l}1.05(0.47 \text { to } 2.35) \\
\mathrm{p} \text { (trend) }=0.917\end{array}$ \\
\hline \multicolumn{5}{|l|}{ Paracetamol } \\
\hline Never & $98(15)$ & $153(17)$ & 1 & 1 \\
\hline$<$ Monthly & $259(39)$ & $424(47)$ & 0.95 (0.71 to 1.28$)$ & $1.06(0.77$ to 1.45$)$ \\
\hline Monthly & $172(26)$ & $219(24)$ & $1.23(0.89$ to 1.69$)$ & $1.22(0.87$ to 1.72$)$ \\
\hline Weekly & $105(16)$ & $97(11)$ & $1.69(1.16$ to 2.46$)$ & $1.79(1.21$ to 2.65$)$ \\
\hline Daily & $30(5)$ & $17(2)$ & $2.76(1.44$ to 5.26$)$ & $\begin{array}{l}2.38(1.22 \text { to } 4.64) \\
\mathrm{p} \text { (trend) }=0.0002\end{array}$ \\
\hline
\end{tabular}

${ }^{\star}$ Controlling for other analgesic and factors listed in table 1 .

Table 3 Association between asthma of differing severity and use of analgesics

\begin{tabular}{|c|c|c|c|}
\hline & $\begin{array}{l}327 \text { cases with mild } \\
\text { asthma (no waking in } \\
\text { past month) } \\
\text { OR }(95 \% \text { CI)* }\end{array}$ & $\begin{array}{l}211 \text { cases with moderately } \\
\text { severe asthma (waking } \\
\text { twice a week or less) } \\
\text { OR }(95 \% \text { CI) }\end{array}$ & $\begin{array}{l}100 \text { cases with very } \\
\text { severe asthma (waking } \\
\text { more than twice a week) } \\
\text { OR }(95 \% C I)^{\star}\end{array}$ \\
\hline \multicolumn{4}{|l|}{ Aspirin } \\
\hline Never & 1 & 1 & 1 \\
\hline$<$ Monthly & $1.10(0.81$ to 1.51$)$ & $1.02(0.69$ to 1.51$)$ & 0.91 (0.49 to 1.69$)$ \\
\hline Monthly & $0.85(0.50$ to 1.46$)$ & $1.01(0.56$ to 1.82$)$ & $1.21(0.47$ to 3.12$)$ \\
\hline Weekly & $0.79(0.40$ to 1.56$)$ & $0.47(0.19$ to 1.21$)$ & $3.17(1.37$ to 7.32$)$ \\
\hline \multirow[t]{2}{*}{ Daily } & $0.93(0.32$ to 2.73$)$ & $0.48(0.10$ to 2.32$)$ & $1.96(0.58$ to 6.70$)$ \\
\hline & $\mathrm{p}($ trend $)=0.600$ & $\mathrm{p}($ trend $)=0.200$ & $\mathrm{p}($ trend $)=0.021$ \\
\hline \multicolumn{4}{|l|}{ Paracetamol } \\
\hline Never & 1 & 1 & 1 \\
\hline$<$ Monthly & 0.92 (0.62 to 1.37$)$ & $0.96(0.58$ to 1.56$)$ & 1.38 (0.68 to 2.82$)$ \\
\hline Monthly & $1.10(0.72$ to 1.68$)$ & $1.28(0.77$ to 2.14$)$ & $1.16(0.53$ to 2.55$)$ \\
\hline Weekly & $1.56(0.95$ to 2.57$)$ & $1.73(0.95$ to 3.13$)$ & $2.50(1.14$ to 5.47$)$ \\
\hline \multirow[t]{2}{*}{ Daily } & $1.35(0.55$ to 3.34$)$ & $2.25(0.90$ to 5.66$)$ & 8.15 (2.84 to 23.40$)$ \\
\hline & $\mathrm{p}($ trend $)=0.048$ & $\mathrm{p}($ trend $)=0.0079$ & $\mathrm{p}($ trend $)=0.0004$ \\
\hline
\end{tabular}

${ }^{\star}$ Controlling for other analgesic and factors listed in table 1 .

ASTHMA AND FREQUENCY OF ANALGESIC USE

Of these individuals, 787 reported taking paracetamol only, 98 aspirin only, 536 were taking both analgesics, and 153 did not report taking either. Frequent (daily/weekly) paracetamol use was reported more commonly by women and by unemployed individuals, and frequent aspirin use by those who were single parents. Aspirin use was similar among cases and controls. However, increasing paracetamol use was strongly associated with asthma (table 2). This association remained after controlling for factors listed in table 1 and for aspirin use ( $\mathrm{p}=$ 0.0002). Compared with never users, the odds ratios (95\% CI) in weekly and daily users were 1.79 (1.21 to 2.65 ) and 2.38 (1.22 to 4.64 ), respectively. Further controlling for gas cooking, ethnicity, total number living in household, use of a car, and receipt of benefits in those 1497 participants with complete information did not alter the findings.

When we compared the effect of frequent (daily/weekly) paracetamol use with less frequent use (including never users) in all individuals, the odds ratio for asthma was 1.73 (95\% CI 1.29 to 2.31 ), p<0.001. When we restricted this analysis to 634 individuals who were also taking aspirin the odds ratio was 2.24 ( $95 \%$ CI 1.30 to 3.89), $p=0.004$. The effect of paracetamol was stronger in men than in women ( $p$ interaction 0.09) but did not differ according to other factors in table 1 or according to reported atopic disease among family members ( $p$ values for interaction all greater than 0.27).
ASTHMA SEVERITY AND FREQUENCY OF ANALGESIC USE

The number of cases with mild, moderately severe, and very severe asthma (classified according to the reported frequency of waking at night with symptoms) was 327,211 , and 100, respectively (26 cases did not report frequency of waking). Table 3 shows associations between analgesic use and asthma when cases of differing severity were compared with controls. The strength of the association between asthma and frequent paracetamol use increased with increasing severity of disease. The association between aspirin use and asthma was inconsistent. There was some evidence that frequent use was less common in moderately severe cases than in controls, but more common in the most severe cases. However, there was no evidence that infrequent (monthly or less) use of aspirin was less common in cases, whatever the severity of disease.

Amongst cases the severity of asthma increased with increasing paracetamol use. The mean increase in square root quality of life score, per frequency of use group, was 0.09 ( $95 \%$ CI 0.04 to 0.13 ), $p=0.0002$. This effect decreased a little to 0.08 ( 0.03 to 0.12$), p=$ 0.0006 , when we controlled for regular use of steroid inhalers. Aspirin use was not associated with asthma severity (mean increase in score $0.02(95 \% \mathrm{CI}-0.03$ to 0.07$), \mathrm{p}=0.49)$.

RHINITIS AND FREQUENCY OF ANALGESIC USE We analysed the association between paracetamol use and rhinitis after controlling for aspirin use and potential confounding factors. Compared with never users the odds ratios (95\% CI) for rhinitis in weekly and daily users were 1.80 (1.11 to 2.91 ) and 2.33 (1.09 to 4.96 ), respectively. The association with rhinitis was present in non-asthmatic but not in asthmatic individuals. Aspirin use was not associated with rhinitis.

INDICATIONS FOR FREQUENT ANALGESIC USE In the main study in 1997 frequent (daily or weekly) analgesic use was reported by 322 participants (172 asthma cases and 150 controls) of whom 220 used paracetamol only, 58 used aspirin only, and 44 used both. We sent a questionnaire to these individuals in January 1999, asking about indications for use and aspirin avoidance, and 102 cases (59\%) and 104 controls $(69 \%)$ responded. Of the respondents, $83 \%$ of cases and $64 \%$ of controls said that they were still taking analgesics daily or weekly. Table 4 shows indications for continuing frequent paracetamol and aspirin use. For both cases and controls the most common indications were headache and general aches and pains. Of cases who used paracetamol frequently, three (4\%) reported taking it for asthma. Of cases who used aspirin frequently, four $(16 \%)$ said they took it for asthma. Among frequent users of paracetamol, $40(56 \%)$ cases and $21(42 \%)$ controls said that they avoided taking aspirin. 
Table 4 Indications for analgesic use among individuals who reported continuing frequent (daily/weekly) use when re-surveyed

\begin{tabular}{|c|c|c|c|c|}
\hline \multirow[b]{2}{*}{ Indication } & \multicolumn{2}{|l|}{ Paracetamol } & \multicolumn{2}{|l|}{ Aspirin } \\
\hline & $\begin{array}{l}\text { Cases } \\
(n=75)\end{array}$ & $\begin{array}{l}\text { Controls } \\
(n=51)\end{array}$ & $\begin{array}{l}\text { Cases } \\
(n=25)\end{array}$ & $\begin{array}{l}\text { Controls } \\
(n=28)\end{array}$ \\
\hline Headache & $61(81 \%)$ & $40(78 \%)$ & $15(60 \%)$ & $15(54 \%)$ \\
\hline Migraine & $14(19 \%)$ & $11(22 \%)$ & $1(4 \%)$ & $4(14 \%)$ \\
\hline Backache/arthritis & $22(29 \%)$ & $13(26 \%)$ & $5(20 \%)$ & $5(18 \%)$ \\
\hline General aches/pains & $26(35 \%)$ & $23(45 \%)$ & $8(32 \%)$ & $6(21 \%)$ \\
\hline Asthma/breathing problems & $3(4 \%)$ & $0(0 \%)$ & $4(16 \%)$ & $0(0 \%)$ \\
\hline Hayfever/nasal allergy/blocked nose & $10(14 \%)$ & $6(12 \%)$ & $3(12 \%)$ & $2(7 \%)$ \\
\hline
\end{tabular}

\section{Discussion}

We have found a strong positive association between frequent (daily or weekly) use of paracetamol and adult asthma in a population based case-control study. Frequent use of paracetamol was also associated with more severe asthma and, in those without asthma, with rhinitis. To our knowledge these observations have not been reported before. We set out a priori to examine the association between paracetamol and asthma and, in view of the small $\mathrm{p}$ values, it seems unlikely that our findings have arisen by chance.

Possible biases need to be considered. Cases and controls were selected from the same clearly defined population of adults registered with 40 general practices. Selection bias seems unlikely as the study was community based and participants were identified before exposure status was measured. Response rates, though not high, were similar in cases and controls. We cannot exclude the possibility that the estimated association between paracetamol and asthma was biased by non-response, but if there was no association in the whole population then paracetamol use would have to be strongly negatively associated with asthma in those individuals who did not take part in the study, which seems unlikely. Our case definition has been used previously in adults of this age, ${ }^{18}$ is predictive of bronchial hyperresponsiveness, ${ }^{19}$ and does not depend exclusively on a doctor's diagnosis. We therefore do not think that our findings can be attributed to increased recognition of asthma in frequent users of analgesics who may attend more frequently for health care. Most importantly, we cannot see why selection, response, or diagnostic biases would result in a strong association between asthma and paracetamol, but not aspirin. Similarly, we know of no reason why asthmatic individuals would have overestimated their use of paracetamol. Although we did not collect detailed information about dose of analgesic used, nor about additional use of paracetamol in compound preparations or in cough and cold remedies, such misclassification is likely to be random with respect to asthma and would tend to lead to an underestimation of the strength of the association.

A strong association between paracetamol and asthma remained after controlling for potential confounders. One possible explanation to consider is that conditions requiring analgesics, and paracetamol in particular, are more common in asthmatic than in nonasthmatic individuals. A recent UK survey of adults found that the predominant reason for taking "over the counter" analgesics such as paracetamol was for non-migrainous headache. ${ }^{24}$ Our findings in the re-survey of frequent analgesic users are in keeping with this. Whilst $\beta_{2}$ agonists can cause headache, this is an uncommon side effect and we found that frequent use of paracetamol for headache was as common in cases who were not on asthma treatment as in those who were. It has been suggested that migraine may be more common in asthmatic individuals, but evidence for a link is contradictory ${ }^{25}$ and a large population based study of young British adults suggested that the association was not strong. ${ }^{26}$ We therefore think it is unlikely that the more frequent use of paracetamol in cases is attributable to a higher prevalence of co-morbidity.

An alternative explanation for our findings might be that cases were taking paracetamol to relieve symptoms associated with asthma. However, in the re-survey only $4 \%$ of cases, who were still taking frequent paracetamol, said that they took it frequently for asthma. A sensitivity analysis suggested that this percentage does not approach that which would be needed to explain the magnitude of association observed with frequent paracetamol use (data not shown). Furthermore, amongst the 25 cases who reported frequent aspirin use, four said that they took it frequently for asthma, which may reflect the bronchodilator action of aspirin in some individuals. ${ }^{27}$

Asthmatic individuals may take paracetamol in preference to aspirin and non-steroidal antiinflammatory drugs (NSAIDs) to avoid potential sensitivity reactions and, in the repeat survey of individuals who were still taking frequent paracetamol, $14 \%$ more cases than controls said that they avoided aspirin. We did not ask participants about use or avoidance of NSAIDs. However, we believe that aspirin avoidance can explain only part of the association between frequent paracetamol use and asthma. Firstly, aspirin use was not less common in cases as a whole than in controls. Secondly, severe cases, who might be most likely to completely avoid aspirin, were just as likely as controls to report infrequent use of aspirin and were significantly more likely to report weekly use. Thirdly, the strong association between frequent paracetamol use and asthma was not restricted to individuals taking paracetamol but not aspirin, but was also found in those taking both analgesics. Aspirin avoidance is even less likely to explain the association between frequent paracetamol use and rhinitis in individuals who did not have asthma.

The graded nature of the association between paracetamol and asthma is in keeping with a causal relation. We speculate that frequent use of paracetamol could contribute to asthma morbidity in a number of ways. In animal models paracetamol can deplete the lung of GSH..$^{15}{ }^{16}$ Recent in vitro studies have shown that incubation with paracetamol at non-cytotoxic and clinically relevant concentrations $(<1 \mathrm{mM})$, which may be achieved in human plasma after therapeutic doses (0.5-1 g) of paracetamol, leads to a decrease in cellu- 
lar GSH concentrations in alveolar macrophages and type 2 pneumocytes from rats ${ }^{28}$ and in human pulmonary macrophages (Dimova and Nemery, personal communication). Depletion of GSH in airway epithelial lining fluid could increase inflammation through loss of antioxidant defences and upregulation of $\mathrm{NF}-\kappa \mathrm{B} .{ }^{12}$ This could cause individuals who would otherwise have subclinical disease to have symptoms, as well as increasing severity of symptoms in those with established asthma. The latter is supported by the inverse association between alveolar GSH levels and bronchial responsiveness in asthmatic adults. ${ }^{10}$ Also, paracetamol can deplete immune cells of $\mathrm{GSH}^{29}$ which, in antigen presenting cells, leads to preferential Th2 cytokine responses ${ }^{30}$ and this might further drive the inflammatory process. GSH is also found in nasal lavage fluid $^{31}$ and hence depletion could also explain the association between frequent paracetamol use and rhinitis. Finally, a few aspirin sensitive asthmatic adults have cross sensitivity to paracetamol following oral challenge with $1 \mathrm{~g},{ }^{32} 33$ and this may go unrecognised because the reduction in lung function is smaller and of slower onset than that seen with aspirin. ${ }^{33}$

Recently, Varner and colleagues proposed that decreasing use of aspirin in favour of paracetamol during the 1980 s in the USA may have contributed to the increase in childhood asthma, ${ }^{34}$ but for entirely different reasons. They suggested that aspirin may protect against asthma through inhibition of prostaglandins and that, as use decreased, so this protection was lost. However, such an explanation would imply that asthma was also common in the more distant past before aspirin was widely introduced, which seems unlikely.

Our findings should be interpreted with caution. A study of this kind cannot establish that the association we have observed is causal. Furthermore, we have shown a clear relation only with daily or weekly paracetamol use. Paracetamol should remain the preferred analgesic and antipyretic because of the potential risks associated with aspirin and NSAIDsnamely, severe sensitivity reactions in those with asthma, gastrointestinal bleeding in adults, and Reye's syndrome in children. However, there may be scope for some individuals who take paracetamol on a daily or weekly basis to reduce their frequency of usage. Furthermore, in a recent survey, $3 \%$ of adult analgesic users reported regularly taking more than the recommended dose. ${ }^{24}$ We believe that there is a need to clarify whether frequent use, and perhaps overuse, of paracetamol contributes to asthma morbidity in the population, particularly in those who have severe disease. Whilst further observational studies in adults and children would be of interest, such clarification can only come from a randomised trial.

The study was funded by the Department of Health. The original asthma survey was funded by the Medical Research Council. We are grateful to Guy Marks and Nimal Premaratne who were involved in that survey, and to Radoslav Latinovic, Margawere involved in that survey, and to Radoslav Latinovic, Marga-
ret Jones and Hossain Azima who helped with data coding and ret Jones and Hossain Azima who helped with data coding and
data management. We also appreciate the helpful comments on data management. We also appreciate the helpful comments on
an earlier draft received from Professor Tak Lee, Professor Stephen Evans, Dr William Maton-Howarth and Dr Peter
Clappison.

1 Barnes PJ. Reactive oxygen species and airway inflammation. Free Radic Biol Med 1990;9:235-43.

2 Kanazawa H, Kurihara N, Hirata K, et al. The role of free radicals in airway obstruction in asthmatic patients. Chest 1991;100:1319-22.

3 Kharitonov SA, Yates D, Robbins RA, et al. Increased nitric oxide in exhaled air of asthmatic patients. Lancet 1994;343: 133-5.

4 Slade R, Crissman K, Norwood J, et al. Comparison of antioxidant substances in bronchoalveolar lavage cells and fluid from humans, guinea pigs, and rats. Exp Lung Res 1993;19: 469-84.

5 Seaton A, Godden DJ, Brown K. Increase in asthma: a more toxic environment or a more susceptible population? Thorax 1994;49:171-4.

6 Cantin AM, North SL, Hubbard RC, et al. Normal alveolar epithelial lining fluid contains high levels of glutathione. $\mathcal{F}$ Appl Physiol 1987;63:152-7.

7 Jenkinson SG, Black RD, Lawrence RA. Glutathione concentrations in rat lung bronchoalveolar lavage fluid: effects of hyperoxia. f Lab Clin Med 1988;112:345-51.

8 Smith LJ, Anderson J, Shamsuddin M, et al. Effect of fasting on hyperoxic lung injury in mice. The role of glutathione. Am Rev Respir Dis 1990;141:141-9.

9 Kelly FJ, Blomberg A, Frew A, et al. Antioxidant kinetics in lung lavage fluid following exposure of humans to nitrogen dioxide. Am F Respir Crit Care Med 1996;154:1700-5.

10 Smith LJ, Houston M, Anderson J. Increased levels of glutathione in bronchoalveolar lavage fluid from patients with asthma. Am Rev Respir Dis 1993;147:1461-4.

11 Kelly FJ, Mudway I, Blomberg A, et al. Altered lung antioxidant status in patients with mild asthma. Lancet 1999;354: $482-3$.

12 Rahman I, MacNee W. Role of transcription factors in inflammatory lung diseases. Thorax 1998;53:601-12.

13 Ketterer B, Coles B, Meyer DJ. The role of glutathione in detoxication. Environ Health Perspect 1983;49:59-69.

14 Kourounakis AP, Rekka EA, Kourounakis PN. Antioxidant activity of guaiazulene and protection against paracetamol hepatotoxicity in rats. F Pharm Pharmacol 1997;49:938-42.

15 Chen TS, Richie JPJ, Lang CA. Life span profiles of glutathione and paracetamol detoxification. Drug Metab Disposition 1990;18:882-7.

16 Micheli L, Cerretani D, Fiaschi AI, et al. Effect of paracetamol on glutathione levels in rat testis and lung. Environ Health Perspect 1994;102(Suppl 9):63-4

17 Premaratne UN, Sterne JAC, Marks GB, et al. Clustered randomised trial of an intervention to improve the management of asthma: Greenwich asthma study. BMF 1999;318: 1251-5.

18 Burney PG, Luczynska C, Chinn S, et al. The European Community Respiratory Health Survey. Eur Respir F 1994; 7:954-60.

19 Burney PG, Chinn S, Britton JR, et al. What symptoms predict the bronchial response to histamine? Evaluation in a community survey of the bronchial symptoms questionnaire (1984) of the International Union Against Tubercunaire (1984) of the International Union Against Tubercu-
losis and Lung Disease. Int F Epidemiol 1989;18:165-73.

20 Marks GB, Dunn SM, Woolcock AJ. A scale for the measurement of quality of life in adults with asthma. 7 Clin Epidemiol 1992;45:461-72.

21 Marks GB, Dunn SM, Woolcock AJ. An evaluation of an asthma quality of life questionnaire as a measure of change in adults with asthma. F Clin Epidemiol 1993;46:1103-11.

22 Marks GB, Burney PG, Premaratne UN, et al. Asthma in Greenwich, UK: impact of the disease and current management practices. Eur Respir f 1997;10:1224-9.

23 Standard Occupational Classification. London: HMSO, 1991.

24 Health Which 9-11 June 1999.

5 Nelson HS. The Bela Schick lecture for 1985. The atopic diseases. Ann Allergy 1985;55:441-7.

26 Strachan DP, Butland BK, Anderson HR. Incidence and prognosis of asthma and wheezing illness from early childhood to age 33 in a national British cohort. $B M 71996 ; 312$. 1195-9.

27 Resta O, Foschino-Barbaro MP, Carnimeo N, et al. Asthma relieved by acetylsalicylic acid and nonsteroid antiinflammatory drugs. Respiration 1984;46:121-7.

28 Dimova S, Hoet PHM, Nemery B. Paracetamol (acetaminophen) cytotoxicity in rat type II pneumocytes and alveo-
lar macrophages in vitro. Biochem Pharmacol (in press)

29 Spielberg SP. Paracetamol toxicity in human lymphocytes in vitro. F Pharmacol Exp Therap 1980;213:395-8.

30 Peterson JD, Herzenberg LA, Vasquez K, et al. Glutathione levels in antigen-presenting cells modulate Th1 versus Th2 response patterns. Proc Natl Acad Sci USA 1998;95:30716.

31 Blomberg A, Sainsbury C, Rudell B, et al. Nasal cavity lining fluid ascorbic acid concentration increases in healthy human volunteers following short term exposure to diesel exhaust. Free Radic Res 1998;28:59-67.

32 Settipane RA, Schrank PJ, Simon RA, et al. Prevalence of cross-sensitivity with paracetamol in aspirin-sensitive asthmatic subjects. F Allergy Clin Immunol 1995;96:480-5.

33 Settipane RA, Stevenson DD. Cross sensitivity with paracetamol in aspirin-sensitive subjects with asthma. $\mathcal{F}$ Allergy Clin Immunol 1989;84:26-33.

34 Varner AE, Busse WW, Lemanske RF Jr. Hypothesis: decreased use of pediatric aspirin has contributed to the increasing prevalence of childhood asthma. Ann Allergy Asthma Immunol 1998;81:347-51. 